\title{
Violence against Women: A Review of Literature with reference to Men Perpetrators
}

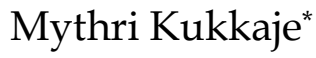

\begin{abstract}
Historically, researchers have studied violence against women through varied lines of enquiry. The literature on the understanding of the phenomenon of violence against women can be broadly classified into two categories: a) studies that examine distinct risk factors and b) studies that propose theoretical frameworks to explain the underlying process that leads to violence. The present study reviews the prominent factors and theories associated with violence against women with reference to perpetrators, specifically, men.
\end{abstract}

Keywords: Gendered-violence, Men Perpetrators, Risk Factors

\section{Introduction}

Factors that influence the decision of a perpetrator to indulge in acts of violence against women have been of interest to researchers for two reasons: one, in order to explain violence and aggression in human behaviour, and two, to develop intervention programs that respond to and prevent violence against women in the society. Researchers have historically studied violence against women in separate lines of enquiry based on the type of violence. Domestic violence and sexual violence are the most frequently studied forms of violence against women. Research in this field in the rest of the world includes exploration and confirmation of various personal,

* School of Health in Social Sciences, University of Edinburgh, United Kingdom; mythrikukkaje@gmail.com 
situational, and socio-cultural factors that influence violence against women. However such studies in the context of India are scarce.

Gendered-violence against women can be classified based on the lifespan of the victim when violated, on the type of consequence on the survivor, on who the perpetrator is and on the space where violence takes place (Watts \& Zimmerman, 2002). Women are victimised at every stage of their lifespan - pre-birth, infancy, childhood, adolescence, young adulthood, middle adulthood, late adulthood, and old age. The consequences on the survivors are physical, sexual, psychological, and economical. The perpetrators could be strangers, acquaintances, friends or relatives including intimate partners of the victimised women. Women are victimised in public spaces, at workplaces and educational institutions, and at homes (Dillon, Hussain, Loxton, \& Rahman, 2013; Dunkle et al., 2004; Himabindu, Arora, \& Prashanth, 2014; Palm, Danielsson, Skalkidou, Olofsson, \& Högberg, 2016; Shannon et al., 2009; Sharma, 2015; Tjaden \& Thoennes, 1998; Visaria, 2008; Watts \& Zimmerman, 2002; World report on violence and health, 2002).

The literature on an understanding of the phenomenon of violence against women can be broadly classified into two categories: studies that examine distinct risk factors and studies that propose theories, models or frameworks to explain the underlying process that leads to violence. The following section outlines the prominent distinct factors and theories from previous studies.

\section{Factors Influencing Violent Behavior Targeted towards Women}

Attitudes and beliefs are significant predictors of behaviour (Taylor, Peplau \& Sears, 2006). Violence-supportive attitudes and beliefs are a result of the socio-cultural background of the individual (Nayak, Byrne, Mutsumi \& Abraham, 2003) and the influence of media and pornography (Hald, Malamuth \& Yuen, 2010). Studies have examined the nature of these violencesupportive attitudes as well as the relationship between these attitudes and factors such as substance use and sociocultural background. 
In an attempt to explore how violence affects the lives of urban youth, Johnson et al. (2005) conducted structured focus group interviews on college male and female students. This study revealed the attitude, thoughts, and beliefs of the participants regarding violence against women. Men saw the use of violence by other men as maintenance of power and dominance in the relationship. This was regarded as acceptable behaviour. Women interpreted acts of violence as commitment and reflection of love. Apart from these findings regarding attitude and beliefs, this study also revealed that men struggled to identify the boundaries of playing and violence (Johnson et al., 2005). This study shows the influence of beliefs both of perpetrators and victims. Beliefs and attitudes are often a reflection of the social fabric, which accepts and permits the perpetration of violence and defines help-seeking behaviour in the face of violence.

Nayak, Byrne, Mutsumi and Abraham (2003) examined the attitudes of men and women undergraduates towards violence against women. This cross-sectional study was conducted across four countries (India, Japan, Kuwait and the United States). Results suggested that more men were subscribed to violence-approving attitudes than women. More importantly, the role of socio-cultural factors was found to be significant in acquiring and maintaining these attitudes - the socio-political, religious, and economic structure of the society influence the individual's understanding of the legitimacy of violence and by extension the use of violence against women.

Apart from the socio-cultural background, media significantly influence attitudes. The portrayal of misogyny, stereotypical gender roles and responsibilities in popular media, and dehumanising representation of women in pornography is problematic. Hald, Malamuth and Yuen (2010) conducted a metaanalysis study on peer-reviewed non-experimental research articles to explore if there had been an association between pornography use and attitudes supportive of violence against women among males. Studies that examined the influence of sexually explicit media, pornography, rape and violence that were created to arouse the viewer sexually on the attitude towards violence against women were included in this meta-analysis. A significant positive 
correlation was found, between pornography use (especially sexually violent pornography) and permissive attitude towards violence against women.

Individual differences moderate the attitudes developed and the violent behaviour in individuals from similar socio-cultural backgrounds (Flood \& Pease, 2009; Hald, Malamuth \& Yuen, 2010). Several personal and situational factors are associated with violent behaviour. These are substance use (Shoreya, Stuarta, McNultyb, \& Moorea, 2014), exposure to violence in childhood (Whitefield et al., 2003) and a few specific personality traits (Febers et al., 2014).

The use of a substance is found to be associated with violent behaviour. Several studies point out that a high number of individuals are under the influence of a substance at the time of their violent behaviour. Substance use is known to lower inhibitions, and by extension cause an error in judgment and result in violent behaviour (Jewkes, 2002). However, the relationship between substance use and violence is unclear. The use of substance might be purposeful so that it can be used as an excuse for unacceptable behaviour (Caetano, Schafer \& Cunradi, 2017; Jewkes, 2002). Shoreya et al. (2014) studied the association of substance use with violent behaviour. This study conducted a daily survey of 90 days on 67 men, who were involved in a dating relationship and consumers of one or more substances. The surveys assessed the extent of alcohol and marijuana consumption, and violent activities (psychological, physical and sexual) in the participants in this duration. The results showed that heavy alcohol use increased the odds of violence directed toward intimate partners. Researchers also noted that marijuana use was not associated with violence.

Another external factor bearing its influence on adult violent behaviour is the childhood experience of violence of an individual. This experience of violence includes personal experience of abuse as well as witnessing violence early in life (Anda et al., 2006; Levenson, Willis \& Prescott, 2016, Santhosh, 2016). Whitefield et al. (2003) conducted a survey of 8,629 participants to examine the association between childhood experiences of violence or witnessing violence. It suggested that risk of becoming a perpetrator of violence in males as adults increased 3.8 fold to men 
who were not exposed to abuse previously. A review paper by di Giacomo and Clerici (2013) summarised several previous studies on the positive association between physical and sexual childhood abuse and perpetrations of violence as adults.

Apart from the external moderators, a few specific innate personality dimensions can make an individual predisposed to use violence. Psychopathic dimensions, narcissism, ill-temper are found to be associated with violent behaviour (Carton \& Egan, 2017; Mouilso \& Calhoun, 2016; Zeigler-Hill, Besser, Morag \& Campbell, 2016). Febers et al. (2014) studied the prevalence of adulthood animal abuse (AAA) in perpetrators of domestic violence and its association with perpetration of intimate partner violence (IPV). They included factors such as alcoholism and antisocial personality traits and their association with AAA and perpetration of IPV. AAA, antisocial personality traits and extent of use of alcohol were measured in 307 men arrested for IPV using questionnaires. It was found that 41 per cent of men attested for IPV had committed at least one act of AAA.

A review of the literature on factors influencing violence against women in India reveals that the majority of the studies are from the victim's point of view. They include studies that examine the incidence rates and forms of violence, the risk factors of facing violence in women or reviews on the policies/laws and their implementation. There is a paucity of studies exploring the predictive factors in men who violate women.

Shrivastava and Shrivastava (2013) studied the extent and forms of domestic violence that influence the risk factors of women and their connections with the treatment-seeking behaviour in women from the slums of Mumbai. Mishra et al. (2014) conducted crosssectional research in Gwalior (an Indian city) for a period of one year in order to identify the prevalence and types of domestic violence, the risk factors for domestic violence and protective factors for married women who are affected by domestic violence. These studies used face-to-face interviews and semi-structured questionnaires on the sample selected by stratified random sampling method. While 36.9 per cent of women who participated in the study reported having experienced some form of domestic violence, 68 of the 144 participants from Gwalior reported having 
faced some form of domestic violence (physical, sexual, emotional or verbal) by their husbands. These studies suggested that age, years of marriage, alcohol consumption, education level and financial dependence of women on their husbands were the risk factors of domestic violence (Mishra et al., 2014; Shrivastava \& Shrivastava, 2013).

The third national family health survey conducted to examine the issues related to domestic violence revealed that irrespective of the socio-economic status of the women, the majority of them accepted the power differences between the genders and believed that men had the right to discipline them (Visaria, 2008). Due to this women do not seek help in the face of violence. Women also tend to refrain from seeking help to maintain family integrity (Shrivastava \& Shrivastava, 2013; Visaria, 2008).

In a correspondence published by Natsal, a British study project of sexual behaviour worldwide called The National Survey of Sexual Attitudes and Lifestyles, it is suggested that prevalence rate of sexual violence is reported to be 8.5 per cent. Only 1 per cent of victims is estimated to report the incident of sexual violence (Raj \& McDougal, 2014). George and Sabarwal (2013) noted that 50.5 per cent of females entered sex work via sex trafficking. This study also found that that the female sex workers are at a higher risk of experiencing physical and sexual violence and of contracting HIV.

In a review paper addressing the gaps between the policies and interpretation, Sharma, Unnikrishnan and Sharma (2015) addressed the inadequacy of the actions undertaken by the Indian Home Ministry to implement the recommendations of the Verma committee. This committee was constituted to look into the policies and laws of India after the Delhi gang-rape incident. Sharma (2015) argued in her address titled "Violence against women: Where are the solutions?" that, violence "is a preventable cause of morbidity and mortality in women" (Sharma, 2015, p. 131). Various forms of violence such as domestic/family violence including dowry-related violence, sexual violence and sexual harassment in the workplace are rampant in India. The mere existence of legislation and discussions about increasing punishment, in some cases even implementation of these punishments serve only to express the frustration surrounding the social issue. It is necessary to work 
towards the prevention of violence and also provide better rehabilitation to victims. The psychiatric illness in victims related to the experience of violence is not adequately addressed. In this elaborate address, risk factors are discussed, albeit mainly from the victim point of view. Factors disfavoring women - the traditional and cultural factors that perpetuate violence are discussed. However, very little is discussed about the factors in perpetrators that facilitate violence (Sharma, 2015).

\section{Theories Explaining the Phenomenon of Violence against Women}

Several theories, models, and frameworks have been proposed that explain the phenomenon of violence against women based on one or more factors of influence. Some of the theories explain specific forms of violence while the others explain violence against women using a comprehensive approach by including all related factors. They explain the phenomenon based on evolutionary, biological, psychological, and socio-cultural perspectives. The evolutionary, biological and psychological perspectives predominantly explain domestic violence. The socio-cultural perspectives explain domestic and sexual violence.

Evolutionary psychologists offer explanations regarding violence and its evolution. Aggression serves a function in specific contexts in social living. It suggests that men are cross-culturally more aggressive than women (Buss \& Shackelford, 1997). The biological theories of violence against women, especially intimate partner violence, are centred on the genetic, congenital and organic causes. Researchers argue brain injury and infections, genetic defects, and neurological defects lead to violent behaviour in human beings (Ali \& Naylor, 2013a).

The psychological perspective of causes of domestic violence is based on personality theories, attachment theory, ill temper and hostility, low self-esteem, and substance use. Individuals with antisocial, borderline, and psychopathy personality dimensions are more aggressive towards their partners (Ali \& Naylor, 2013a). The nature of attachment with the romantic partner determines the representation of self and the partner. A disturbance in either of 
representations leads to aggression between partners (Ali \& Naylor, 2013a; Flood \& Pease, 2009).

The socio-cultural perspective of violence against women includes the feminist perspective and the social learning perspective. The feminist perspective argues that patriarchal and misogynistic attitude sanctions violence against women in the pretext of power control. This causes women to experience learned helplessness and the exhibit the battered women syndrome. This increases the incidence of violence against women (Ali \& Naylor, 2013b; Flood \& Pease, 2009). The social-cultural perspective also proposes that violence-supportive attitudes can be acquired through social learning. Early life exposure to stereotypical gender roles, sexist mindset and violence as a valid means of resolving conflicts incites violent behaviour (Ali \& Naylor, 2013b; Pease \& Flood, 2008).

The range of theories proposed hitherto to explain the phenomenon of violence against women appears to be extensive. However, no single theory explains all forms of violence because they do not consider all the influencing factors at the same time. For example, evolutionary psychology and biological theories fail to consider the social and situational factors that influence violent behaviour. Feminist theories maintain that patriarchy and sexism as the main reason for violence against women while failing to account for individual and situational factors. Personality theories leave out social and situational factors. Moreover, they associate violent behaviour with mental illness. Hence it is essential to derive a theory that integrates all the factors that result in this phenomenon.

In such an attempt, Heise (1998) proposed a framework that integrated many factors as predictors of sexual aggression and violence against women in general. This framework "conceptualizes violence as a multifaceted phenomenon grounded in the interplay among personal, situational, and sociocultural factors" (Heise, 1998, p.262). Heise applied the multidimensional approach proposed earlier by other researchers to organise research on child abuse to rough treatment meted out to the wives, to a wider area of violence against women. The framework, thus proposed, identified four levels of factors. 
The first level is the personal history of the individual, which includes the childhood experience of abuse and neglect and witnessing abuse as a child. The second level is the microsystemthe context in which violence takes place, which includes factors such as male dominance and control within the family, alcohol use, and marital conflict. The third level is the exosystem - constituting the social context, which includes socioeconomic status, isolation of women and association with delinquent peers. The fourth level is the macrosystem - attitudes at the cultural level, which includes male entitlement, hostile masculinity, rigid gender roles and acceptance of violence (Heise, 1998). A review of this framework suggests that this model efficiently integrates several discrete factors identified as influential before and after this framework was proposed. However, Heise acknowledges that despite the breadth of the theory, it might not be complete yet. There may be a few more factors that need to be adequately studied and added to the framework.

\section{Conclusion}

Even though the literature on contexts that breed perpetrators of violence is expansive, there are a few gaps as pointed out in the review. First, a majority of the studies are conducted on nonoffending population. Second, the contexts in which studies regarding influencing factors are conducted are significantly different from the Indian context. Third, the theories explaining the phenomenon do not consider the whole range of factors that influence violent behaviour. Fourth, the major focuses of the studies are on the victim-narratives. In order to intervene the violent behaviour effectively, more studies are recommended focusing on the perpetrators who are identified as offenders. Methods to maintain better behaviour and abandon the tendency to perpetrate also have to be developed. 


\section{References}

Ali, P. A., \& Naylor, P. B. (2013). Intimate partner violence: A narrative review of the biological and psychological explanations for its causation. Aggression and Violent Behavior, 18(3), 373-382.

Ali, P. A., \& Naylor, P. B. (2013). Intimate partner violence: A narrative review of the feminist, social and ecological explanations for its causation. Aggression and Violent Behavior, 18(6), 611-619.

Anda, R. F., Felitti, V. J., Bremner, J. D., Walker, J. D., Whitfield, C. H., Perry, B. D., ... \& Giles, W. H. (2006). The enduring effects of abuse and related adverse experiences in childhood. European Archives of Psychiatry and Clinical Neuroscience, 256(3), 174-186.

Buss, D. M., \& Shackelford, T. K. (1997). Human aggression in evolutionary psychological perspective. Clinical psychology review, 17(6), 605-619.

Caetano, R., Schafer, J., \& Cunradi, C. B. (2001). Alcohol-related intimate partner violence among white, black, and Hispanic couples in the United States. Alcohol Research \& Health, 25(1), 58-58.

Carton, H., \& Egan, V. (2017). The dark triad and intimate partner violence. Personality and Individual Differences, 105, 84-88.

Di Giacomo, E., \& Clerici, M. (2013). 1733-Physical and sexual violence as risk factors for those who commit acts of rape and pedophilia. European Psychiatry, 28, 1.

Dillon, G., Hussain, R., Loxton, D., \& Rahman, S. (2013). Mental and physical health and intimate partner violence against women: A review of the literature. International Journal of Family Medicine, 2013, 115.

Dunkle, K. L., Jewkes, R. K., Brown, H. C., Gray, G. E., McIntryre, J. A., \& Harlow, S. D. (2004). Gender-based violence, relationship power, and risk of HIV infection in women attending antenatal clinics in South Africa. The Lancet, 363(9419), 1415-1421.

Febres, J., Brasfield, H., Shorey, R. C., Elmquist, J., Ninnemann, A., Schonbrun, Y. C., et al. (2014). Adulthood animal abuse among men arrested for domestic violence. Violence against Women, 20(9), 10591077.

Flood, M., \& Pease, B. (2009). Factors influencing attitudes to violence against women. Trauma, Violence, \& Abuse, 10(2), 125-142.

George, A., \& Sabarwal, S. (2013). Sex trafficking, physical and sexual violence, and HIV risk among young female sex workers in Andhra 
Pradesh, India. International Journal of Gynecology \& Obstetrics, 120(2), 119-123.

Hald, G. M., Malamuth, N. M., \& Yuen, C. (2010). Pornography and attitudes supporting violence against women: revisiting the relationship in nonexperimental studies. Aggressive Behavior, 36(1), 1420.

Heise, L. L. (1998). Violence against women an integrated, ecological framework. Violence against women, 4(3), 262-290.

Himabindu, B. L., Arora, R., \& Prashanth, N. S. (2014). Whose problem is it anyway? Crimes against women in India. Global Health Action, 7(1), 23718.

Jewkes, R. (2002). Intimate partner violence: causes and prevention. The Lancet, 359(9315), 1423-1429.

Johnson, S. B., Frattaroli, S., Campbell, J., Wright, J., Pearson-Fields, A. S., \& Cheng, T. L. (2005). "I Know What Love Means." Gender-based violence in the lives of urban adolescents. Journal of Women's Health, 14(2), 172-179.

Levenson, J. S., Willis, G. M., \& Prescott, D. S. (2016). Adverse childhood experiences in the lives of male sex offenders: Implications for trauma-informed care. Sexual Abuse, 28(4), 340-359.

Mishra, A., Patne, S. K., Tiwari, R., Srivastava, D. K., Gour, N., \& Bansal, M. (2014). A cross-sectional study to find out the prevalence of different types of domestic violence in Gwalior city and to identify the various risk and protective factors for domestic violence. Indian journal of community medicine: official publication of Indian Association of Preventive \& Social Medicine, 39(1), 21.

Mouilso, E. R., \& Calhoun, K. S. (2016). Personality and perpetration: Narcissism among college sexual assault perpetrators. Violence against women, 22(10), 1228-1242.

Nayak, M. B., Byrne, C. A., Martin, M. K., \& Abraham, A. G. (2003). Attitudes toward violence against women: A cross-nation study. Sex Roles, 49(7-8), 333-342.

Palm, A., Danielsson, I., Skalkidou, A., Olofsson, N., \& Högberg, U. (2016). Violence victimisation - a watershed for young women's mental and physical health. The European Journal of Public Health, 26(5), 861-867.

Raj, A., \& McDougal, L. (2014). Sexual violence and rape in India. Women, 2001, 124.

Santhosh, K. R. (2016). A Review on the Perpetrators of Child Abuse. Review of Social Sciences, 1(3), 45-52. 
Shannon, K., Kerr, T., Strathdee, S. A., J Shoveller, J., Montaner, J. S., \& Tyndall, A. W. (2009). Prevalence and structural correlates of gender based violence among a prospective cohort of female sex workers. $B M J, 2939,339$.

Sharma, I. (2015). Violence against women: Where are the solutions?. Indian Journal of Psychiatry, 57(2), 131.

Sharma, P., Unnikrishnan, M. K., \& Sharma, A. (2014). Sexual violence in India: addressing gaps between policy and implementation. Health policy and planning, 30(5), 656-659.

Shorey, R. C., Stuart, G. L., McNulty, J. K., \& Moore, T. M. (2014). Acute alcohol use temporally increases the odds of male-perpetrated dating violence: A 90-day diary analysis. Addictive behaviors, 39(1), 365-368.

Shrivastava, P. S., \& Shrivastava, S. R. (2013). A study of spousal domestic violence in an urban slum of Mumbai. International journal of preventive medicine, 4(1), 27.

Taylor, S. E., Peplau, L. A., \& Sears, D. (2006). Attitudes and Attitude Change. In S. E. Taylor, L. A. Peplau, \& D. Sears, Social Psychology (12th ed.), pp. 132-168. Upper Saddle River, N.J: Pearson/Prentice Hall.

Tjaden, P., \& Thoennes, N. (1998). Prevalence, Incidence, and Consequences of Violence against Women: Findings from the National Violence against Women Survey. Research in Brief. Retrieved from http:/ / files.eric.ed.gov/fulltext/ED434980.pdf

Visaria, L. (2008). Violence against women in India: Is empowerment a protective factor?. Economic and Political Weekly, 60-66.

Watts, C., \& Zimmerman, C. (2002). Violence against women: global scope and magnitude. The Lancet, 359(9313), 1232-1237.

Whitfield, C. L., Anda, R. F., Dube, S. R., \& Felitti, V. J. (2003). Violent childhood experiences and the risk of intimate partner violence in adults: Assessment in a large health maintenance organization. Journal of Interpersonal Violence, 18(2), 166-185.

World Report on Violence and Health (Eds), Krug, E. G., Dahlberg, L. L., Mercy, J. A., Zwi, A. B. \& Lozano, R. 2002. Retrieved from http://www.who.int/violence_injury_prevention/violence/global_c ampaign/en/chap6.pdf

Zeigler-Hill, V., Besser, A., Morag, J., \& Campbell, W. K. (2016). The Dark Triad and sexual harassment proclivity. Personality and Individual Differences, 89, 47-54. 